\title{
Oceanography
}

CITATION

Dybas, C.L. 2012. Ripple marks-The story behind the story. Oceanography 25(2):10-14,

http://dx.doi.org/10.5670/oceanog.2012.59.

$\mathrm{DOI}$

http://dx.doi.org/10.5670/oceanog.2012.59

COPYRIGHT

This article has been published in Oceanography, Volume 25, Number 2, a quarterly journal of The Oceanography Society. Copyright 2012 by The Oceanography Society. All rights reserved.

USAGE

Permission is granted to copy this article for use in teaching and research. Republication, systematic reproduction, or collective redistribution of any portion of this article by photocopy machine, reposting, or other means is permitted only with the approval of The Oceanography Society. Send all correspondence to: info@tos.org or The Oceanography Society, PO Box 1931, Rockville, MD 20849-1931, USA. 


\title{
Ripple Marks The Story Behind the Story by cheryl lyn dybas
}

\section{Savannas of the Sea}

\author{
Mtumbwi hauwezi kujua panapokuwa pamejaa maji. (Swahili) \\ The dugout canoe does not know the depth of the water. (English)
}

So believe the Hangaza, an ethnic group of more than 150,000 people who live to the west of Tanzania's Serengeti National Park. Lake Victoria there has long been an object of contemplation for the Hangaza.

They know it has fish and crocodiles, but say there's more to this-and other-vast waterbodies than what may be seen from a canoe.

Half a world away along the US West

Coast, marine scientists studying the

California Current would agree. The oceanographers are finding new ways of looking beneath research vessels-even high-tech ones-that ply Pacific Ocean waters. They're getting a fish-eye view of the deep by placing electronic tags on predators such as blue whales and California sea lions, yellowfin tuna and white sharks.

The project is called Tagging of Pacific Ocean Predators (TOPP). It focuses on certain Pacific Ocean areas, among them the California Current. This undersea river of water flows south along the western coast of North America, beginning off British Columbia and ending near Baja California. It supports large populations of whales and seabirds, and fuels important fisheries. The current's productivity comes from the upwelling of cold subsurface waters, caused by prevailing northeasterly winds. The cold waters ferry a steady supply of nutrients to the surface.

TOPP scientists are also tracking marine animals along a trans-oceanic highway called the North Pacific Transition Zone. The zone connects the western and eastern Pacific at the boundary between cold subarctic water and warmer subtropical water about halfway between Hawaii and Alaska.

Like the African plains that surround Lake Victoria, these huge expanses of the North Pacific Ocean are major corridors for the movements of predators and prey.

Findings from TOPP, which began in 2000, were recently reported in the journal Nature. They reveal that the migrations of 23 marine species overlap-a picture of critical marine life pathways and habitats.

"These are the oceanic areas where food is most abundant," says marine scientist Barbara Block of Stanford University's Hopkins Marine Station. "They're the savanna grasslands of the sea."

Knowing where and when species migrate is critical information in efforts to manage and protect ecosystems, says ecologist Daniel Costa of the University of California, Santa Cruz.

Block and Costa were joined by scientists Steven Bograd of the National Oceanic and Atmospheric Administration's (NOAA's) Southwest Fisheries Science Center in La Jolla, California, Randy Kochevar of Stanford University, and others in launching TOPP. The project was part of the Census of Marine Life, a 10-year research initiative

California sea lion; Laysan albatross; team working with male elephant seal. Photo credits: Daniel Costa

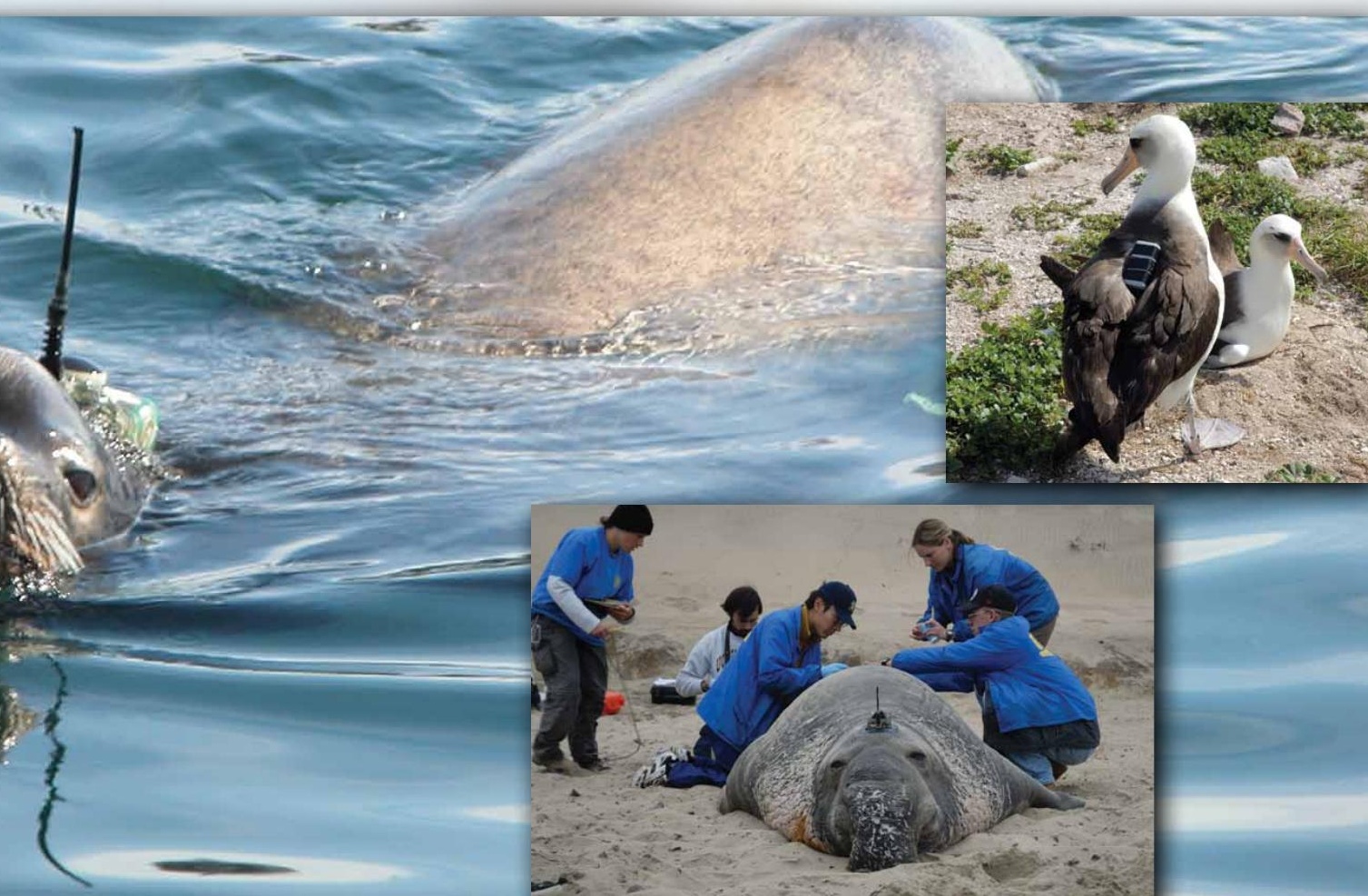


that investigated the diversity, distribution, and abundance of marine life in the global ocean. TOPP became the world's largest "biologging" study, involving more than 75 biologists, oceanographers, engineers, and computer scientists in five countries.

"It was like looking across the entire African savanna," says Block, "and trying to figure out: Where are the watering holes a zebra or a cheetah might frequent? Where are the fertile valleys? Where are the deserts that animals might avoid, and the migratory corridors that species such as wildebeest use to travel from place to place?"

She and colleagues are answering these questions for marine animals from bluefin tuna, to blue whales, to leatherback sea turtles.

The scientists used an array of technologies to track species and record such environmental variables as water temperature, salinity, and depth. The project deployed 4,306 electronic tags, yielding a huge amount of data, says Costa. TOPP scientists spent two years synthesizing datasets. They discovered intersecting ocean hotspots and highways of ocean life-and how marine conditions influence where animals hang out.

The results suggest that water temperature is key to the seasonal migrations of many North Pacific Ocean species. That's especially true in the marine ecosystem defined by the California Current. The study reveals that the current is a marine savanna where whales, sharks, seals, seabirds, turtles, and tunas migrate annually.

"The Serengeti, too, is an ecosystem that's synonymous with animal movements," says ecologist Grant Hopcraft of the Frankfurt Zoological Society-Africa, headquartered in the Serengeti. "Each year more than one and a half million ungulates cross its plains." Their seasonal migrations follow cyclic rains that lead to the growth of savanna grasses. Where grasses sprout up, ungulates such as wildebeest follow. Predators like lions trail closely behind.

This grand march of the animals isn't unique, Hopcraft says.

"The movements of marine species in the California Current are similar to those in the

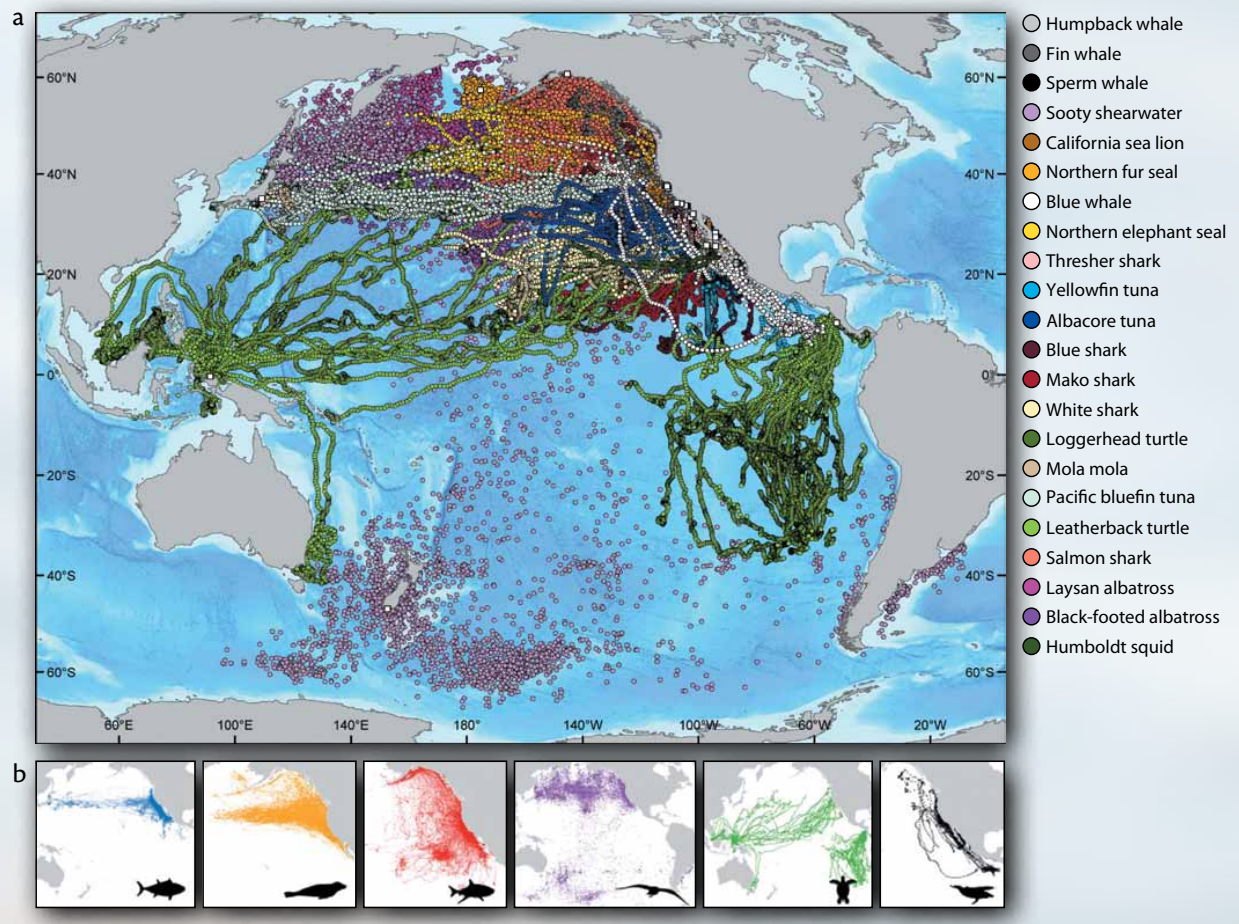

Marine scientists tracked humpback whales and mako sharks, yellowfin tuna and leatherback turtles-along with 19 other species-as they migrated through Pacific Ocean waters, a blue Serengeti. Reprinted by permission from Macmillan Publishers Limited, Block et al., 2011, Nature 475:86-90, http://dx.doi.org/10.1038/nature10082.

Serengeti," he says, "which begs the question: why? Research at the population level suggests that it's a changing food supply that drives animal migrations. But recent animal collaring projects in the Serengeti show a huge amount of variation in individual species' responses."

There's a lot more going on, Hopcraft believes, beneath the surface. "For the Serengeti-and the California Current-does an animal's internal condition determine how it responds? Is it remembering previous routes and responding to the same cues? How will environmental change affect these great migrations of the land and the sea?"

Roaring African lions and barking

California sea lions may have much to say to each other.

TOPP results show that many migratory marine species, like animals in the Serengeti grasslands, return to the same regions each year, homing in with astonishing fidelity, says Block, to the places where they were first tagged.

"It's akin to a student from London studying in far-off Rome and coming home each summer at the same moment-but doing it all in the dark without a map or compass, using only his or her internal sense of position and direction," says Costa.

Take the White Shark Café, a remote midPacific area where great white sharks gather in winter and spring. TOPP researchers discovered that the sharks frequently travel to and stay in the area. While at the café, sharks dive to depths of $300 \mathrm{~m}$ as often as once every 10 minutes. The purpose of the dives is unknown, but the sharks linger, often for months, in an oceanic "desert" where food is thought to be scarce.

How the shark café came to be isn't yet understood. Tracking other species, such as tuna, may lead to an explanation.

Some predators, like California sea lions, spend their lives in the California Current, but others migrate long distances across the Pacific Ocean to reach abundant prey like krill, sardines, anchovies, and squid.

"Why a young bluefin tuna less than two years old wakes up in the light of the Japan Sea and decides to swim to Baja is unknown," Block says. "But once it arrives, 
tagging data indicate that it lives there for years, taking advantage of the rich 'forage' along the coast."

The scientists have found that several species-including leatherback sea turtles, black-footed albatrosses, sooty shearwaters, bluefin tunas, and salmon sharks-migrate more than 2,000 km from the western, central, or southern Pacific Ocean to reach the California Current's rich food resources. The commute is equal to the distance between Seattle and San Diego.

Tunas, sharks, and blue whales are also cued to seasonal changes in ocean primary productivity, Bograd and others are discovering.
These marine predators ultimately follow plankton, the grasslands of the sea.

The scientists also looked at the partitioning of habitats by closely related species. Certain tunas, for example, prefer particular water temperatures; these preferences correlate with physiological differences. Some species are adapted to living in colder waters than others.

"We can now predict when and where individual species are likely to be in a given ocean region, and begin to understand the factors that control where they go next," says Costa. He and other scientists believe this is the basis of ecosystem-based management.
Following TOPP, Block and colleagues are spawning a new effort to study the blue Serengeti. "Where are the hot spots needing immediate protection?" she asks. "We plan to conduct the ecosystem science that reveals who's at watering holes like White Shark Café and, most importantly, why.

"There's an amazing Africa-like game park in the waters off the West Coast. It will take enormous vision to protect this wild place. Without conservation of such ocean realms, the bluefin tuna and blue whales, whale sharks and great whites might not be there in future generations."

Hopcraft's thoughts echo Block's. He imagines animal migrations like those in the African savanna-and the Pacific Ocean-"as the inhalations and exhalations of our planet. They're the telltale signs of a healthy world."

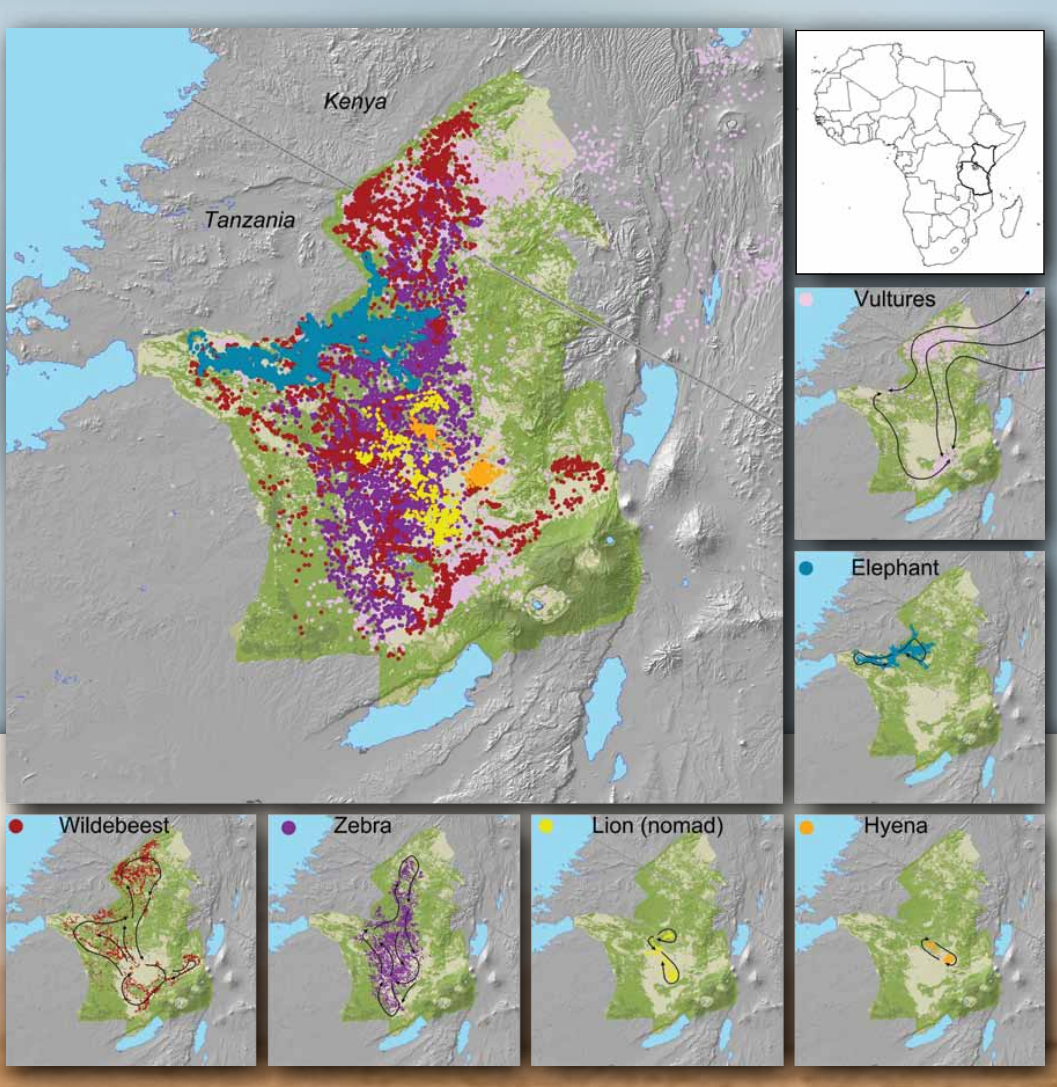

MAP | The seasonal migration of wildebeest and zebras around the Serengeti ecosystem is tracked by commuting hyenas and nomadic lions that follow the moveable feast. GPS collar data from vultures suggest they forage near high-density herds.

Elephants tend to roam over vast areas throughout the Serengeti woodlands, but frequently return to favorite locations. Credit: Grant Hopcraft (University of Glasgow \& the Frankfurt Zoological Society) with Meggan Craft (University of Minnesota), Anna Estes (University of Virginia), and Corinne Kendall (Princeton University \& the Peregrine Fund)

PHOTO | One of many lion prides that shifts its range in response to the annual migration of wildebeest in the Serengeti. Photo credit: Daniel Rosengren 


\section{Cometh the (Mercury-Laden) Fog}

Some 16 wetlands along Siberian crane flyways have international importance. This necklace of wetlands extends from Poyang Lake in China through Russia and into Kazakhstan and Iran.

"All have something to tell us about the future of Asia's water resources, and about the Siberian cranes that depend on them," says Mirande.

Poyang Lake, for example, once had a surface area of $3,500 \mathrm{~km}^{2}$ and an average depth of $8 \mathrm{~m}$. Due to drought and water storage at the upstream Three Gorges Dam, the lake has been reduced to $200 \mathrm{~km}^{2}$.

Poyang provides habitat for half a million migratory birds. During winter months, it's home to flocks of migrating Siberian cranes. More than $90 \%$ of the world population of these cranes, estimated at about 3,200 birds, spends the season there.

ICF scientists are coordinating a long-term monitoring effort at Poyang Lake.

The winter of 2010-2011 offered the biologists a chance to see how Siberian cranes respond to a lack of their preferred food. ICF researcher James Burnham observed behavior no one had seen before: Siberian cranes foraging in grasslands far from water. He and others are analyzing what the cranes were eating, and how that might affect the birds' health.

Major floods at Poyang in the summer of 2010 destroyed much of the aquatic vegetation that serves as a primary food source for the cranes. The following winter, "they behaved like birds stressed and in trouble," says Harris.

If the trend continues, it could lead to poor reproduction in Siberia in the brief arctic summers that follow. The adults might lack the fat reserves, gained during winters on Poyang Lake, for successful breeding.

As the wetlands fare, so, too, the cranesand ultimately us.

The world lies in moonlit drops shaken from a crane's bill.
What do a horror movie, the roof of a building situated in a West Coast redwood forest, a bluff in California chaparral, and a research vessel in Monterey Bay have in common?

They're often draped in long tendrils of fog. That makes them prime sites for collecting fog water samples, in all but the cliffhanger film, that is.

And maybe even there, says atmospheric chemist Peter Weiss of the University of California at Santa Cruz (UCSC).

Weiss had a hunch that sea fog carried toxic mercury and monomethyl mercury ashore. As he and colleagues report in a recent issue of the journal Geophysical Research Letters (GRL), fog is indeed an important but previously overlooked way monomethyl mercury circulates in coastal environments.

Other researchers had found high levels of mercury in Monterey Bay during coastal upwelling events. That gave Weiss and co-authors the idea to don trench coats instead of lab coats to find out whether the mercury was somehow stealing ashore in fog.

"It started out as a hometown case," Weiss says, "that quickly went national."

Mercury is a heavy metal neurotoxin that bioaccumulates and bioconcentrates, primarily as monomethyl mercury, in aquatic food webs. It often reaches high levels in fish and other animals, making them unsafe for human consumption.

The source of monomethyl mercury in aquatic organisms has been debated, says Weiss, "but atmospheric deposition has been implicated as a pathway." Presumably, this mechanism includes all forms of precipitation, the scientists wrote in their GRL paper: rain, snow, and fog.

By dark of night from June 13, 2011, through August 28, 2011, the researchers collected fog samples. They worked only after sundown so there would be no decomposition of mercury from sunlight, moving a single fog water collector among four locations near Santa Cruz: the roof of a UCSC building that's $230 \mathrm{~m}$ above sea level and $6 \mathrm{~km}$ inland in a redwood forest; a bluff at UCSC's Long Marine Laboratory, $10 \mathrm{~m}$ above sea level in chaparral; the Moss Landing Marine Laboratory's research vessel John $\mathrm{H}$. Martin, $5 \mathrm{~m}$ above sea level in Moss Landing Harbor; and while the John H. Martin was near a mooring $20 \mathrm{~km}$ offshore in Monterey Bay.

The average monomethyl mercury concentration in the fog water samples was five-fold greater than the previously reported highest monomethyl mercury values in rainwater. "There are no monomethyl mercury measurements in fog water in the scientific literature," says Weiss, "but these elevated concentrations suggest that fog could be a significant source in coastal environments."

Could fog be a vector for not only mercury, but other toxic elements? Is it possible that substances like pesticides could be hidden in the mist?

"We really don't know," says Weiss. "The potentially far-reaching consequences of these results, however, underscore the need to collect fog water in various coastal environments."

When Weiss walks down his driveway to pick up the morning paper, he wonders what's in the dew. "If my feet are wet when I get back in," he says, "I'm thinking: 'it was foggy enough last night to get a good sample."'

Calling the Trenchcoat Brigade. 